\title{
Children are waiting for care and answers
}

\author{
Geoffrey K. Blair MD
}

$\infty \quad$ See related research paper by Zamakhshary and colleagues, page 1001

$\mathrm{C}$ hildren have been implicitly ignored in the recent national 10-year action plan to establish benchmarks for wait times for health care, as noted by Dr. Brian Postl, former federal advisor on wait times. ${ }^{1}$ In this issue of CMAJ Zamakhshary and colleagues provide a scientific analysis of how long infants and young children with inguinal hernias should wait for surgery. ${ }^{2}$ The authors approached this question from the perspective of avoidance of harm, evaluating the rate of incarceration during the wait for surgery. They appropriately focused on infants and children less than 2 years of age, because inguinal hernias are more often incarcerated in this age group than in older patients. Their results are surprising and disturbing: while waiting for surgery, $16.8 \%$ of the infants and young children were seen in an emergency department at least once and $11.9 \%$ had an incarcerated hernia.

One could question the validity of their data sources. Indeed the authors do. Administrative databases of the use of emergency health services in Canada have been cited as weak with regards to their clinical detail and quality of data. ${ }^{3}$ Unfortunately, the limitations of these databases apparently precluded the authors from doing a more detailed analysis to differentiate children with an incarcerated hernia requiring immediate surgery from mislabelled difficult-to-reduce hernias not requiring immediate surgery. This is an important differentiation, because the latter group might have included children taken to the emergency department by parents who were anxious about the bulge reappearing but who had not been educated about its simple reduction.

One could also call into question the definition of wait time and how it can be distinguished from a clinically appropriate observation period in this context. The risk to a boy's testes when incarceration occurs, even with prompt surgical repair, is known beyond doubt. However, testicular atrophy may also be an unfortunate long-term result of the elective surgery. ${ }^{4}$ A 1995 Canadian study by pediatric general surgeons observed potential testicular damage after hernia repair in $9.3 \%$ of boys less than 6 months of age. ${ }^{5}$ Thus, we must balance our enthusiasm for a prompt elective repair against the real risk of iatrogenic injury, especially in the tiny infant with delicate tissues.

Moreover, when does the wait-time clock start? Zamakhshary and colleagues appropriately denoted the wait time to be from the time of diagnosis to surgery. ${ }^{2}$ However, parents may perceive the wait time to be longer. Some children may have been referred to a surgeon without a specific diagnosis, and the parents perhaps had anxiously waited to get an initial

\section{Key points}

- Timeliness of health care is integral to the quality of health care.

- Children to a large extent have been ignored in the debate on surgical wait times in Canada.

- Ensuring timely repair of inguinal hernias may involve more than simply additional surgical resources.

- New national initiatives are seeking to identify a broader strategy for monitoring, studying and managing wait times for infants and children needing surgery.

appointment. A recent Canadian survey of parents of children waiting for elective noncritical surgery revealed that, although the parents acknowledged some willingness to wait, 50\% regarded the wait as deleterious to their child's health; $83 \%$ regarded a wait of more than 3 months as unacceptable. ${ }^{6}$ The factors contributing to their dissatisfaction may be more than the natural concern for their child's well-being. The wait for surgery may also incur economic hardship if the parents have to take time off work to care for their child or travel great distances for preoperative testing and consultations.

Zamakhshary and colleagues conclude that the safe wait time for surgery to repair an inguinal hernia in infants and young children is 2 weeks or less. ${ }^{2}$ If a longer wait means a proportion will come to harm and require urgent surgery to save the incarcerated structures, what then is a testicle or ovary worth? Health economists can calculate the cost of ensuring that all infants and young children undergo hernia repair within 14 days after diagnosis. Our knee-jerk response might be simply to call for more operating room time, resources and personnel. However, there may be better solutions. ${ }^{7}$ For instance, infants and young children with an inguinal hernia could be appropriately stratified into urgent, less urgent and even "wait-and-see" groups. This approach may offer a more effective strategy to manage the surgical needs of this population.

To date, babies with painful hernias have had no political voice in the process of allocating health care resources. We need more studies of issues concerning surgical access for children. We also need better information systems that can track and monitor wait times.

The Leitch report ${ }^{8}$ and the Postl report ${ }^{1}$ both call for better information regarding children's health and health care na-

Geoffrey Blair is with BC Children's Hospital and the Department of Surgery, University of British Columbia, Vancouver, BC 
tionally. Health Canada recently announced major funding for the Canadian Paediatric Surgical Wait Times Project. ${ }^{9}$ The second stage of this project, with the unprecedented collaboration of all 16 pediatric academic health centres of Canada, the commitment of the Pediatric Surgical Chiefs of Canada, of which I am one, and the assistance of Canadian Child and Youth Health Coalition, will seek to identify a broader strategy for monitoring, studying and managing wait times for children needing surgery. Children are waiting, too - for answers that can be obtained only through proper attention to their problems of health care access.

Competing interests: None declared.

Acknowledgement: Geoffrey Blair is Chair of the Pediatric Surgical Chiefs of Canada.

\section{REFERENCES}

1. Postl BD. Final report of the Federal Advisor on Wait Times. Ottawa (ON): Health Canada; 2006. Available: www.hc-sc.gc.ca/hcs-sss/alt_formats/hpb-dgps/pdf/pubs /2006-wait-attente/index-eng.pdf (accessed 2008 Sept 25).

2. Zamakhshary M, To T, Guan J, et al. Risk of incarceration of inguinal hernia among infants and young children awaiting elective surgery. CMAJ 2008;179: $1001-5$.

3. Kennedy S, Young W, Schull MJ, et al. The need for a national emergency health services database. CJEM 2008;10:120-4.

4. Misra D. Inguinal hernias in premature babies: Wait or operate? Acta Paediatr 2001;90:370-1.

5. Walc L, Bass J, Rubin S, et al. Testicular fate after incarcerated hernia repair and/or orchiopexy performed in patients under 6 months of age. J Pediatr Surg 1995;30:1195-7.

6. Miller GG. Waiting for an operation: parents' perspectives. Can J Surg 2004;47: 179-81.

7. Siciliani L, Hurst J. Tackling excessive waiting times for elective surgery: a comparative analysis of policies in 12 OECD countries. Health Policy 2005;72:201-15.

8. Leitch KK. Reaching for the top. A report by the Advisor on Healthy Children and Youth. Ottawa (ON): Health Canada; 2007. Available: www.hc-sc.gc.ca/hl-vs/pubs /child-enfant/advisor-conseillere/index-eng.php (accessed 2008 Sept 25).

9. Government of Canada announces funding for the Canadian Paediatric Surgical Wait Times Project — stage II [press release]. Ottawa (ON): Health Canada; 2008 June 12. Available: www.hc-sc.gc.ca/ahc-asc/media/nr-cp/_2008/2008_91-eng.php (accessed 2008 Oct 8).

Correspondence to: Dr. Geoffrey K. Blair, Chief of Pediatric Surgery, BC Children's Hospital, 4480 Oak St., Vancouver, BC V6H 3V4; fax 604 875-3213; gblair@cw.bc.ca 